\title{
Thermodynamic analysis of an ecologically restored plant community:Theoretical basis
}

\author{
Mingli Chen ${ }^{1}$, Zijian $\mathrm{Wu}^{2}$, Xinxi $\mathrm{Fu}^{1}$, Linnan Ouyang ${ }^{3}$, and Xiaofu $\mathrm{Wu}^{4}$ \\ ${ }^{1}$ Central South University of Forestry and Technology \\ ${ }^{2}$ Hunan Academy of Forestry Science \\ ${ }^{3}$ China Eucalypt Research Centre, State Forestry and Grassland Administration \\ ${ }^{4}$ Affiliation not available
}

May 18, 2020

\begin{abstract}
The nature of matter and energy exchange of an ecological process defines the applicability of the thermodynamic functions for describing an ecosystem. A plant community is an open system consisting of living species as material components. Following the basic laws of thermodynamics, the enthalpy $\mathrm{H}$ stored in biomass form of a plant community will be related to its total equivalent biomass quantity $\mathrm{CT}$, the weighted average standard chemical potential $\mu 0$, Gibbs free energy $\mathrm{G}$, entropy $\mathrm{S}$ and temperature $\mathrm{T}$ by $\mathrm{H}=\mathrm{G}+\mathrm{TS}=\mathrm{CT} \mu 0$. Using $\mathrm{h}, \mathrm{f}$ and $\mathrm{s}$ to denote $\mathrm{H} /(\mathrm{RT}), \mathrm{G} /(\mathrm{RT})$ and $\mathrm{S} / \mathrm{R}$ (R denoting the gas constant), respectively, the conventional function can be transformed to $\mathrm{h}=\mathrm{f}+\mathrm{s}=\mathrm{CT} \mu 0 /(\mathrm{RT})$. The relation $\operatorname{sm} / \mathrm{CT}=\mathrm{SIm}=\ln (\mathrm{N})$ derived from the maximal discrete entropy theorem shows that sm (the maximum $\mathrm{s}$ ) and SIm (the maximum information entropy) will increase with increase in the total number of species $\mathrm{N}$, suggesting that $\mathrm{N}$ has an upper limit Nm subject to regional species resource. As an upper limt of SI and $\mathrm{s} / \mathrm{CT}, \ln (\mathrm{N})$ is applied as a biodiversity index. As an upper limt of $\ln (\mathrm{N}), \ln (\mathrm{Nm})$ can thus be regarded as a biodiversity potential index as it takes into account the available number of species distributed in the surrounding areas of the plant community, showing the potential limit for further increase in its biodiversity. The difference between $\ln (\mathrm{Nm})$ and $\ln (\mathrm{N})$ dtermines the distribution of $\mathrm{H}$ as $\mathrm{G}$ and $\mathrm{TS}$, indicating that the internal energy distribution of an acosystem is a function of its productivity and biodiversity. The potential trends of increasing $\mathrm{N}$ towards $\mathrm{Nm}$ and increasing $\mathrm{s}$ towards sm suggest that an ecosystem can possess natural trends towards increase in both its species richness and evenness.
\end{abstract}

\section{Hosted file}

Manuscript 1 Theoretical basis.docx available at https://authorea.com/users/318787/articles/ 452164-thermodynamic-analysis-of-an-ecologically-restored-plant-community-theoreticalbasis

\section{Hosted file}

Figures 1.docx available at https://authorea.com/users/318787/articles/452164-thermodynamicanalysis-of-an-ecologically-restored-plant-community-theoretical-basis 